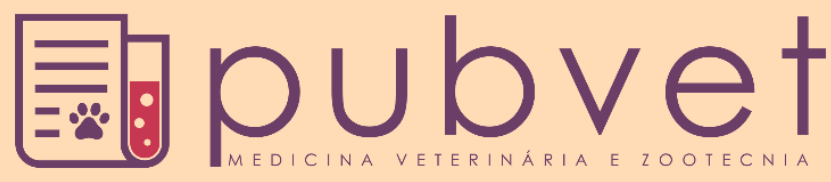

https://doi.org/10.31533/pubvet.v14n9a653.1-14

\title{
Biossíntese de lignina em plantas submetidas ao déficit hídrico
}

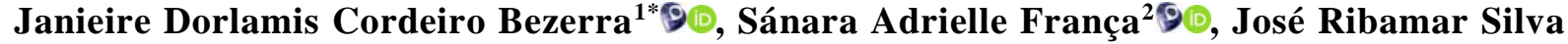

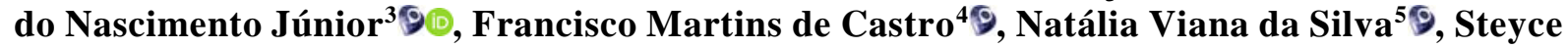 \\ Neves Barbosa ${ }^{2} \theta$
}

${ }^{I}$ Doutora em Zootecnia pela Universidade Federal da Paraíba, Departamento de Zootecnia, Areia-PB, Brasil. ${ }^{2}$ Doutoranda em Ciência Animal pela Universidade Federal do Vale do São Francisco, Petrolina-PE, Brasil.

${ }^{3}$ Professor Substituto da Universidade Federal do Rio Grande do Norte, Departamento de Zootecnia, Macaíba-RN, Brasil.

${ }^{4}$ Professor da Escola Superior Batista do Amazonas, Curso de Medicina Veterinária, Manaus-AM, Brasil.

${ }^{5}$ Doutoranda em Zootecnia pela Universidade Federal Rural de Pernambuco, Departamento de Zootecnia, Recife-PE, Brasil.

*Autor para correspondência: E-mail: janieirebezerra@hotmail.com

Resumo. Em seus ecossistemas, as plantas são submetidas a diversos potenciais inimigos, tanto os bióticos como os abióticos. No entanto, os vegetais por meio de mutações, seleção natural e mudanças evolutivas desenvolveram mecanismos de defesa não só estruturais como também ao nível metabólico, o que proporcionou o surgimento de compostos tóxicos, retardantes e mais isolantes, os quais foram transferidos para os seus descendentes. Esses compostos são classificados como metabólitos secundários, os quais são subdivididos em três grupos: terpenos, compostos fenólicos e compostos nitrogenados. O grupo dos compostos fenólicos é o mais heterogêneo, dentre os compostos desse grupo a lignina é a substancia mais abundante no vegetal, perdendo apenas para a celulose. Esta macromolécula fenólica possui uma constituição complexa com ramificações em três dimensões, mas de forma geral é formada pelos álcoois coniferil, cumaril e sinapil. A lignina proporciona maior rigidez estrutural, durabilidade dos tecidos, transporte de água nos vasos do xilema e funciona como uma barreia a ação patogênica, contudo, pouco se sabe sobre essa dinâmica. Acredita-se que controles genéticos e fisiológicos complexos atuem modulando a expressão de genes de lignina e que suas respostas ao déficit hídrico variam em função da espécie e da intensidade e duração do estresse, no qual as respostas das enzimas poderiam ser expressas isoladamente ou em conjunto, com a mesma cinética ou não. A elucidação da biossíntese da lignina contribuirá para os programas de melhoramento, para a formulação de modelos matemáticos e para um melhor manejo de pastagens.

Palavras chave: coniferil, cumaril, enzimas, peroxidases, sinapil

\section{Biossíntese de lignina em plantas submetidas a déficit}

Abstract. In ecosystems, plants are subjected to many potential enemies, both biotic and
abiotic. However, vegetables through mutation, natural selection, and evolution developed
defense mechanisms changes not only structural but also the metabolic level, which
resulted in the appearance of toxic compounds, and more insulating retardants, which have
been transferred to their descendants. These compounds are classified as secondary
metabolites which are divided into three groups: terpenes, phenolic compounds, and
nitrogen compounds. The group of phenolic compounds is the most heterogeneous among
the compounds of this group lignin is the most abundant substance in the plant, second only
to cellulose. This phenolic macromolecule has a complex branching in three dimensions,
but the overall constitution is formed by coniferyl, coumaryl alcohols, and sinapil. Lignin
provides greater structural rigidity, durability of fabrics, water transport in xylem vessels
and acts as a obstacle the pathogenic action, however, little is known about this dynamic. 
It is believed that complex genetic and physiological controls act by modulating the expression of genes of lignin and their responses to drought vary depending on the species and the intensity and duration of stress, in which the responses of enzymes could be expressed alone or together with the same kinetics or not. The elucidation of the biosynthesis of lignin contribute to the improvement programs, formulation of mathematical models and for better management of rangelands.

Keywords: coniferyl, coumaril, enzymes, peroxidases, sinapil

\section{Biosíntesis de lignina en plantas sometidas a déficit hídrico.}

Resumen. En los ecosistemas, las plantas están sujetas a muchos enemigos potenciales, tanto bióticos como abióticos. Sin embargo, los vegetais a través de la mutación, la selección natural y la evolución desarrollaron cambios en los mecanismos de defensa no solo estructurales sino también a nivel metabólico, lo que resultó en la aparición de compuestos tóxicos y más retardantes aislantes, que se transfirieron a sus descendientes. Estos compuestos se clasifican como metabolitos secundarios que se dividen en tres grupos: terpenos, compuestos fenólicos y compuestos de nitrógeno. El grupo de compuestos fenólicos es el más heterogéneo entre los compuestos de este grupo. La lignina es la sustancia más abundante en la planta, solo superada por la celulosa. Esta macromolécula fenólica tiene una ramificación compleja en tres dimensiones, pero la constitución general está formada por coniferilo, alcoholes cumarilo y sinapil. La lignina proporciona una mayor rigidez estructural, durabilidad de los tejidos, transporte de agua en los vasos de xilema y actúa como barreia, la acción patogénica, sin embargo, se sabe poco sobre esta dinámica. Se cree que los controles genéticos y fisiológicos complejos actúan modulando la expresión de genes de lignina y sus respuestas a la sequía varían según la especie y la intensidad y duración del estrés, en el que las respuestas de las enzimas podrían expresarse solas o junto con el misma cinética o no. La aclaración de la biosíntesis de la lignina contribuye a los programas de mejora, formulación de modelos matemáticos y para un mejor manejo de los pastizales.

Palabras clave: coniferilo, cumaril, enzimas, peroxidasas, sinapil

\section{Introdução}

Em seus ecossistemas, as plantas são submetidas a fatores estressantes, tanto os bióticos como os abióticos. No entanto, os vegetais por meio de mutações, seleção natural e mudanças evolutivas desenvolveram mecanismos de defesa não só estruturais como também ao nível metabólico, o que proporcionou o surgimento de compostos tóxicos, retardantes e mais isolantes. Esses compostos são classificados como metabólitos secundários e subdivididos em três grupos: terpenos, compostos fenólicos e compostos nitrogenados.

O grupo mais heterogêneo é o dos compostos fenólicos, com presença de compostos de natureza lipídica, glicosídica, ácidos carboxílicos, etc. Nesse grupo a lignina é a substância mais abundante no vegetal. Esta macromolécula fenólica possui uma constituição complexa, mas de forma geral é formada pelos álcoois coniferil, cumaril e sinapil, sendo que suas proporções variam em função da espécie, do crescimento e do desenvolvimento.

A lignina proporciona maior rigidez estrutural, durabilidade dos tecidos, transporte de água nos vasos do xilema, funciona como uma barreira a ação patogênica, é responsável pela inibição do crescimento e pela complexação dos carboidratos e proteínas. As tensões bióticas e abióticas conduzem ao aumento da lignificação da parede celular ou a mudança de sua estrutura através das ações enzimáticas, entretanto pouco se sabe sobre essa dinâmica.

Acredita-se que controles genéticos e fisiológicos complexos atuem modulando a expressão de genes de lignina e que suas respostas ao déficit hídrico variam em função da espécie, da intensidade e duração do estresse, no qual as respostas das enzimas poderiam ser expressas isoladamente ou em conjunto, com a mesma cinética ou não. A elucidação da biossíntese da lignina contribuirá para os programas de 
melhoramento, para a formulação de modelos matemáticos e para um melhor manejo de pastagens. Portanto, objetivou-se compreender os mecanismos de síntese de lignina de plantas submetidas ao déficit hídrico.

\section{Metabolismo secundário}

Os vegetais possuem dois tipos de metabolismos: o primário, que é responsável pelos processos fotossintéticos, respiratórios e no transporte de solutos, no qual os compostos envolvidos possuem uma distribuição universal nas plantas, e o secundário, responsável pela produção de compostos de defesa, isolamento e dos que atraem polinizadores, sendo que os compostos que participam deste metabolismo variam entre espécies e dentro das espécies, visto que determinados compostos são mais requeridos em algumas plantas do que em outras em função do estresse biótico ou abiótico ao qual estão submetidos (Moura et al., 2010; Taiz \& Zeiger, 2004).

A produção de metabólitos secundários foi passada de geração a geração por meio de mecanismos como mutações, seleção natural e mudanças evolutivas, ou seja, precisou-se de milhares de anos de interações com os fatores bióticos e abióticos para que as plantas desenvolvessem os mecanismos de adaptação, proteção e para a polinização. Algumas plantas, por exemplo, produzem substancias de natureza inseticida ou fungicida que possuem ação no sistema nervoso, endócrino ou respiratório e que são acumulados em grande quantidade nas plantas. Os glicosídeos cianogênicos, por exemplo, são acumulados nos vacúolos das folhas da Manihot esculenta, quando os herbívoros ou insetos mastigam essa planta os glicosídeos cianogênicos entram em contato com as enzimas hidrolíticas do citossol e liberam ácido cianídrico $(\mathrm{HCN})$, que inibe a cadeia transportadora de elétrons, causando asfixia (Taiz \& Zeiger, 2004).

O número de compostos formados por este metabolismo foi de aproximadamente $140.000 \mathrm{em} 2003$, sendo que este metabolismo é dividido em três grandes grupos: terpenos, compostos fenólicos e compostos nitrogenados (Figura 1).

Os terpenos são considerados o maior grupo, são sintetizados a partir do acetil CoA pela rota ácido mevalônico ou dos intermediários glicolíticos pela rota do metileritritol fosfato (MEP). Suas estruturas básicas são denominadas de unidade isoprênicas ou simplesmente isoprenóides. Alguns terpenos possuem ação no crescimento e no desenvolvimento dos vegetais como é o caso dos hormônios giberelinas (diterpeno) e ácido abscísico e dos carotenoides, outros agem em defesa do vegetal produzindo óleos essenciais (monoterpenos e sesquiterpenos) como o mentol e o limoneno ou produzindo esteroides como as fitoecdisonas e as saponinas.

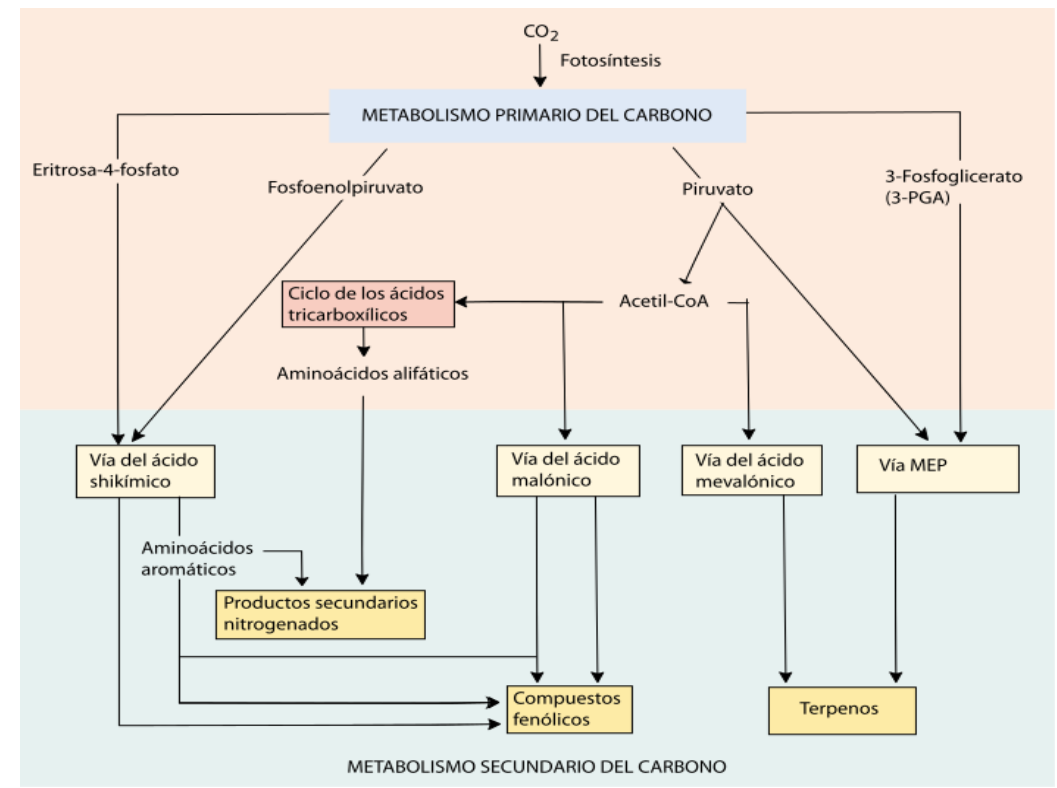

Figura 1. Metabolismo secundário do carbono. Fonte: (Taiz \& Zeiger, 2004). 
Os compostos fenólicos são constituídos de grupo fenol e são quimicamente heterogêneos, alguns possuem natureza lipídica, outros são ácidos carboxílicos e outros são glicosídeos solúveis. A principal via para a sua formação são pela rota chiquímica, que converte os carboidratos em aminoácidos aromáticos dentre os quais a fenilalanina, que é um intermediário na biossíntese da maioria dos compostos fenólicos. Alguns compostos fenólicos simples são ativados pela luz UV como é o caso dos ácidos p-cumárico e seus derivados e do ácido cafeico, outros são liberados no solo com o intuito de inibir o crescimento de outras plantas (alelopatia) como o ácido cafeico e o felúrico. A lignina é um composto fenólico de possui a capacidade de proporcionar suporte mecânico, resistência física e estabilidade química e os flavonoides (antocianinas, flavonas, flavonóis e isoflavonas) podem contribuir para atrair os animais para a polinização, proteger contra danos causados pela luz UV, ter ação antimicrobiana como é o caso das isoflavonas ou ação ao ataque de herbívoros como é o caso dos taninos.

Os compostos nitrogenados mais conhecidos são os alcaloides e os glicosídeos cianogênicos, os quais podem provocar efeitos fisiológicos drásticos nos animais como a nicotina, a cocaína e a estricnina e outros podem ser grandes aliados como a morfina (analgésico) e a lupinina (restabelecimento do ritmo cardíaco). Os aminoácidos não-protéicos e algumas proteínas vegetais como a lectina agem na defesa contra a herbivoria.

As ações desses metabólitos ocorrem de forma indireta e varia em função da espécie ou grupo de espécies. Além disso, suas ações muitas vezes ocorrem em conjunto, onde a formação de um determinado composto ocorre pela ligação de subunidades derivadas de diferentes vias. Salienta-se que os genes para a síntese dos metabolitos secundários foram conservados nos genomas das plantas superiores e que pode haver inclusive genes latentes (Grotewold, 2005).

O metabolismo secundário possui importância ecofisiológica nas plantas, no qual o estresse abiótico como as mudanças de temperatura, estado da água, os níveis de luz, ultravioleta (UV) exposição e nutrientes minerais, modulam a expressão de genes e a transdução dos sinais. A função ecológica do metabolismo secundário pode ter efeitos benéficos como fitomedicamentos, principalmente como anestésicos (Briskin, 2000), como flavorizantes e conservantes.

Na nutrição animal os compostos secundários são vistos de forma negativa, uma vez que o excesso desses compostos pode provocar baixa digestibilidade e toxidez. Assim, durante anos o metabolismo secundário foi sinônimo de antinutricional. Contudo, trabalhos recentes demostram que esses metabólitos possuem propriedades antioxidantes (Kaur \& Kapoor, 2008), e que quando utilizados em concentrações moderadas, podem melhorar a nutrição e contribuir para a redução da carga parasitária, como ocorre com a utilização dos taninos condensados e das saponinas, salientando-se ainda que os compostos secundários possam ter diferentes mecanismos de ação antiparasitárias, sendo interessante oferecer para os animais uma dieta diversificada o que aumentaria a eficácia e reduziria os efeitos colaterais prejudiciais (Copani et al., 2013). Em trabalhos como os de Singer et al. (2009) e de Villalba \& Landau (2012), observou-se que os animais parasitados possuíam maior preferência de consumo de alimentos que possuíam compostos secundários que proporcionavam eleitos antiparasitários.

Nesse sentido, o bioma da caatinga possui uma diversidade de plantas ricas em compostos secundários que necessitam serem estudadas, principalmente, sob o ponto de vista da sanidade e nutrição animal. Pouco se sabe sobre as dinâmicas metabólicas desses vegetais, hipoteticamente, sua produção de compostos secundários estão mais associados aos fatores abióticos do que os bióticos, principalmente, aqueles relacionados as adaptações as altas temperaturas, radiações solares e ao déficit hídrico. Consequentemente, acredita-se que determinadas rotas metabólicas são mais requeridas do que outras. Na literatura são escassos trabalhos que estudem a defesa dos vegetais contra os meios abióticos, necessitando de maiores conhecimentos sobre essas dinâmicas.

\section{Biossíntese dos compostos fenólicos: a produção da lignina}

Os compostos fenólicos são um grupo muito diversificado de fitoquímicos, de estruturas simples ou complexas, constituídos de um grupo fenol que englobam desde moléculas simples até moléculas mais complexas e altamente polimerizadas. Podem ser encontrados nos vegetais tanto livres como ligados a 
carboidratos e proteínas. A formação destes compostos ocorre sob condições estressantes como o déficit hídrico, radiação UV, ferimentos e infecções (Naczk \& Shahidi, 2004).

Embora haja várias rotas para a sua biossíntese, a mais utilizada é a rota chiquímica, a qual converte os percussores de carboidratos nos aminoácidos aromáticos fenilalanina, tirosina e triptofano, sendo que a fenilalanina é responsável pela produção da maioria dos compostos (Figura 2). A enzima fenilalanina amonialiase (PAL) é a responsável pela formação do ácido cinâmico a partir da fenilalanina. Quando o ácido cinâmico recebe uma hidroxila há a formação o ácido $p$-cumárico que pode seguir por quatro vias: $1^{\circ}$ ) Formação dos ácidos cafeicos e de outros fenilpropanoides simples (contém um anel bezenico), $2^{\circ}$ ) Formação das gumarinas, $3^{\circ}$ ) Formação de percussores de lignina, $4^{\circ}$ ) Formação do $p$-cumaril-CoA, que pode tanto formar as flavononas como os percussores de lignina (Taiz \& Zeiger, 2004).

Os compostos fenólicos são responsáveis pela adstringência, estabilidade oxidativa, atividades antialérgica, anticarcinogênica, antimicrobianas e contribuem para as qualidades sensoriais (cor, flavour e sabor). Possuem ação de neutralização de radicais livres, sendo que esta atividade varia em função da sua estrutura, especificamente do número e posição das hidroxilas, e da natureza das substituições dos anéis aromáticos.

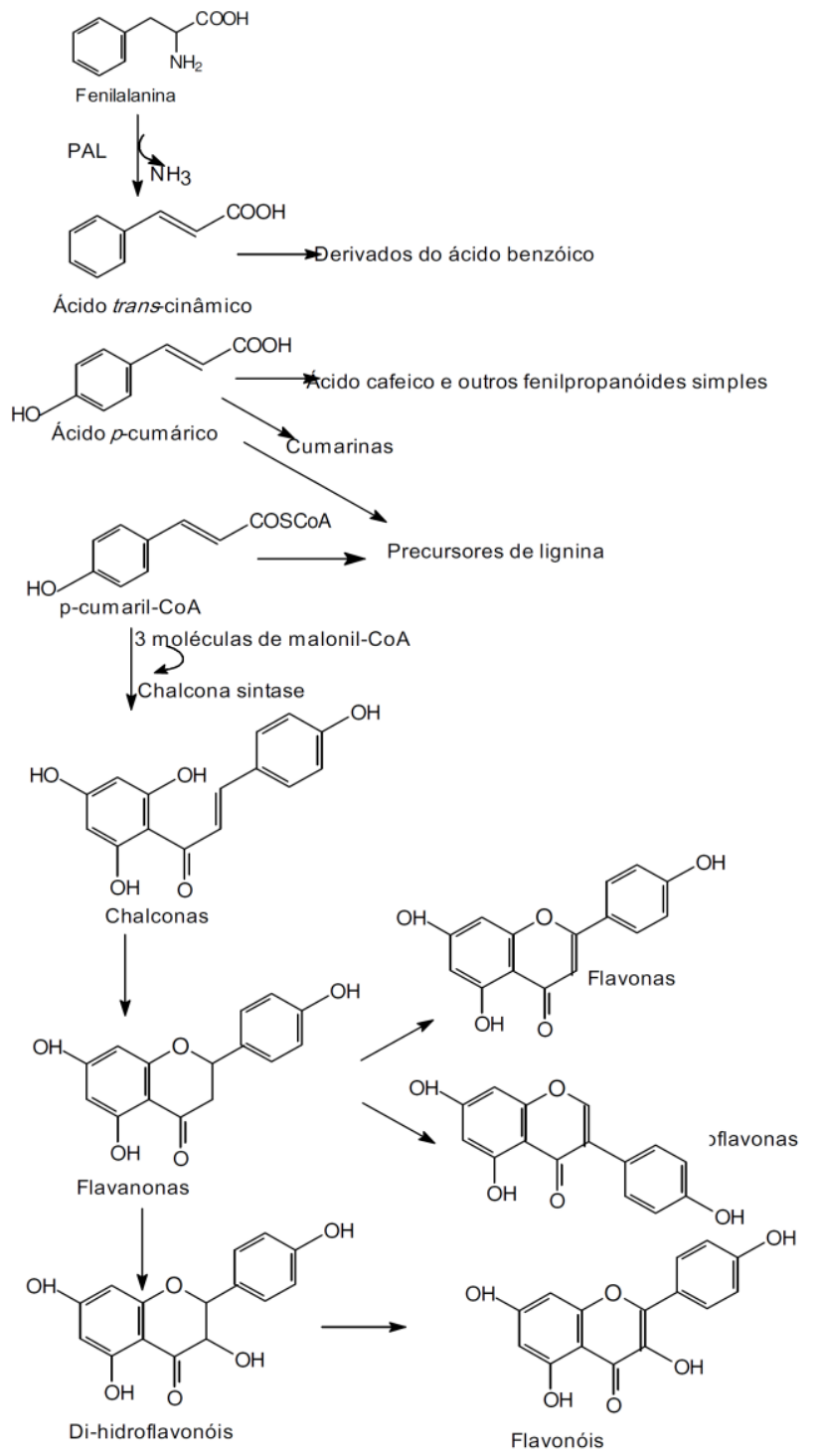

Figura 2. esquema da biossíntese de compostos fenólicos a partir da fenilalanina. Fonte: Taiz \& Zeiger (2004).

Salienta-se que a atividade antioxidante aumenta com o aumento do grau de hidroxilação, sendo que a substituição dos grupos de hidroxila nas posições 3 e 5 por grupos metoxila reduz essa atividade. Os 
compostos fenólicos são divididos em três classes: ácidos fenólicos, flavonóides, estilbenos e taninos (Balasundram et al., 2006; Kim et al., 2003).

No caso dos ácidos fenólicos, estes são compostos simples formados por um anel aromático, subdivididos em dois grupos: $1^{\circ}$ ) formados pelos ácidos hidroxibenzóicos (C6-C1), tais como os ácidos gálico, p-hidroxibenzóico, protocatecuico, vanílico e siríngico; $2^{\circ}$ ) Formados pelos ácidos hidroxicinâmicos (C6-C3), como os ácidos caféico, ferúlico, p-cumárico e sinápico (Soares, 2002).

A lignina é encontrada nos órgãos que necessitam de maior aporte de força como o caule, especificamente nos tecidos do esclerênquima, tornando-se mais intensa a dia deposição quando o alongamento celular cessa (Vanholme et al., 2010). Conforme Wilson (1994) essa deposição na parede celular se dá através da lamela média/parede primária para a parede celular secundária. A lignina tem grande influência na digestibilidade, principalmente quanto ao seu arranjo e o tipo de percussores que o formam, por exemplo, o ácido p-cumarico e ferúrico estão diretamente envolvidos na associação da lignina com a hemicelulose.

A lignina pode ser visualizada por meio de colorações histoquímicas como a coloração Fasga e a Maule. A coloração Fasga, constituída pelos corantes safranina e astra blue ou azul de alcian, permite verificar se o material apresenta ou não lignina, pois o azul possui afinidade com a celulose e a safranina com a lignina (Figura 3). O corante de Maule além de permitir identificar os tecidos lignificados permite identificar o tipo de lignificação, se siringil ou guaiacil, onde a coloração alaranjada indica a lignina siringil e a amarelada a guaiacil.

A lignina é um termo genérico para um grande grupo de polímeros aromáticos, é uma macromolécula fenólica complexa, amorfa, de natureza recalcitrante, derivada de unidades fenilpropanóides (ou álcoois hidroxicinamil ou monolignóis) denominadas $\mathrm{C}_{6} \mathrm{C}_{3}$ ou $\mathrm{C}_{9}$ (fenilalanina, tirosina e triptofano) que são repetidas de forma irregular. Este polímero faz parte da parece celular e dos vasos condutores, é responsável pela resistência mecânica e contribui no transporte de água, nutrientes e metabólitos, sendo responsável pela resistência. A lignina possui grande diversidade estrutural, variando tanto entre espécies como na própria espécie, razão pela qual este polímero possui constituição difícil de ser estabelecida. Além disso, observa-se que este polímero inibe o aproveitamento dos carboidratos estruturais pelo animal (Saliba et al., 2001; Taiz \& Zeiger, 2004).

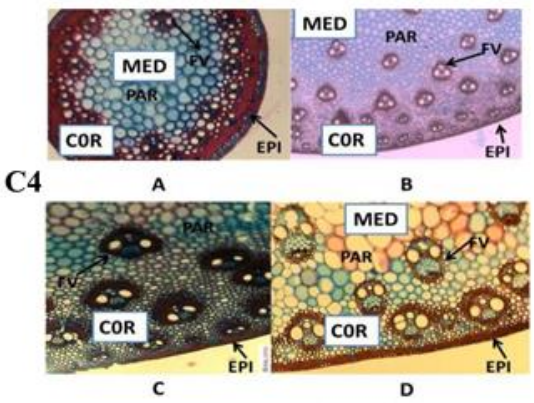

C D 1- Secções transversais dos colmos de plantas C4 e CAM. Em C4: A = Braquiária; B = Milheto; C= Sorgo e D = Milho. Em CAM: $\mathrm{A}=$ Mandacaru; $\mathrm{B}=$ Palma Miúda; $\mathrm{C}=$ Facheiro e $\mathrm{D}=$ Xique-xique. $\mathrm{COR}=$ córtex; $\mathrm{MED}=$ região medular; $\mathrm{EPI}=$ epiderme; $\mathrm{Par}=$ Parêquima; $\mathrm{FV}=$ feixe vascular; $\mathrm{HC}=$ hipoderme colenquimática; $\mathrm{CS}=$ câmara subestomática; $\mathrm{DR}=$ drusas; $\mathrm{CUT}=$ cutícula e $\mathrm{AM}=$ células com amiloplastos.

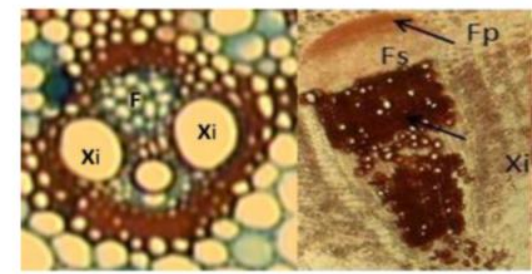

2- Visão dos feixes vasculares de uma $\mathrm{C} 4$ e $\mathrm{CAM}$, respectivamente. $\mathrm{Xi}=$ xilema; $\mathrm{F}=$ floema; $\mathrm{Fp}=$ floema primário; Fs = floema secundário.

Figura 3. Cortes histológicos de gramíneas e palma forrageira coloridas com o corante Fasga. Fonte: Bezerra et al. (2014). 

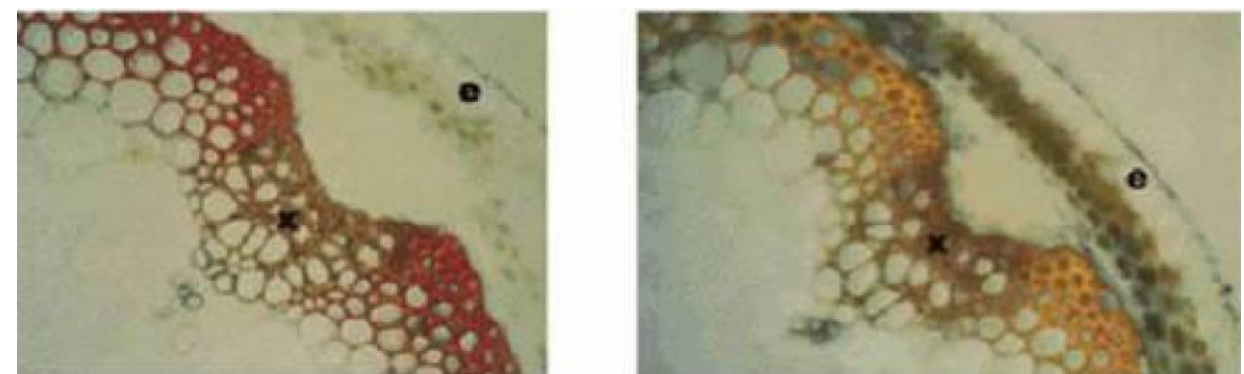

Figura 4. Cortes histológicos de Arabidopsis com o reagente de Mäule que reage com lignina siringil - coloração amarela. O mutante de Arabidopsis é incapaz de sintetizar lignina siringil. Fonte: Bauer et al. (2008).

Embora a lignina não apresente uma estrutura definida, sua composição se dá basicamente pelas unidades de álcoois sinapil (siringil), coniferil (guaiacil) e p-cumarico (p-hidroxifenil) (Figura 5). As enzimas envolvidas no processo de formação da lignina são basicamente hidroxicinamato CoA ligase (CCL), cinamil CoA redutase (CCR), cinamil álcool NADP oxiredutase (CAD) e as peroxidades. A síntese desses monolignóis ocorre a partir da fenilalanina que é obtida no plastídio pela via chiquímica (Rippert et al., 2009), esse aminoácido é canalizado pelas enzimas fenilalanina amônia-liase (PAL) e C4H. Buxton (1996) ao comparar a composição da lignina entre as gramíneas e as leguminosas observaram que os ácidos ácido p-cumarico, ácido ferúlico e ácido sinápico são mais elevados nas gramíneas do que nas leguminosas. Além disso, a quantidade dessas unidades não segue nenhum padrão nas plantas e estas podem produzir a lignina ajustando a rota, visto que ao ter a produção do álcool coniferil inibida a planta cresceu e produziu lignina, demostrando a papel vital desse polímero (Ralph, $\underline{1996)}$.

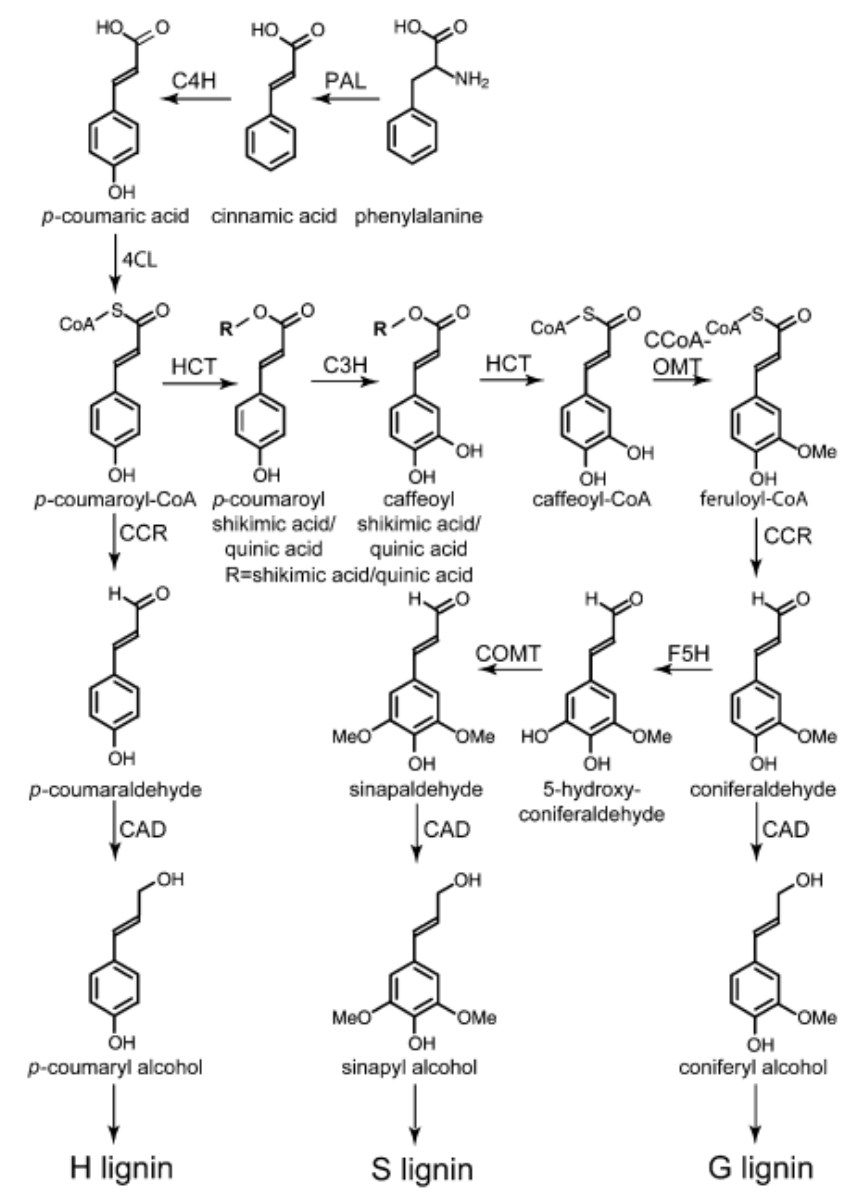

Figura 5. A principal rota biossintética para os monolignóis p-cumaril, coniferil e o álcool sinapyl (Boerjan et al., 2003). PAL, Fenilalanina amônia liase; $\mathrm{C} 4 \mathrm{H}$, cinamato 4-hidroxilase; 4CL, 4-cumarato: CoA-ligase; C3H, p-coumarato 3hidroxilase; HCT, p-hidroxicinamoil-CoA: Quinate/Chiquimato p-hydroxycinnamoyltransferase; CCoAOMT, Cafeoil-CoA-O-metiltransferase; CCR, cinamoil-CoA redutase; F5H, ferulato 5-hidroxilase; COMT, cafeico acid Ometiltransferase; CAD, cinamil álcool desidrogenase. Fonte: Vanholme et al. (2010). 
Este composto pode ser classificado conforme a sua susceptibilidade relativa à hidrólise em lignina core e lignina não core. A primeira se refere à lignina formada pelas unidades de p-hidroxifenila, quaiacila e siringila em diferentes porporção, que proporcionam maior condensação e maior resistência a degradação. Já o não core são formados pelos ácidos p-hidroxicianâmico, que são liberados via hidrólise (Saliba et al., 2001).

Após a sua biossíntese, os monolignóis são translocados para a parede celular por um mecanismo que permanece ainda não conhecido. Há apenas hipóteses: $1^{\circ}$ ) os monolignóis são glicosilados após a sua chegada na parece celular; $2^{\circ}$ ) os monolignóis são transportados para a membrana do plasma por vesículas derivadas de Golgi; $3^{\circ}$ ) os monolignóis são translocados através da membrana plasmática por transportadores. Contudo, nenhuma das hipóteses são convincentes. Uma nova tendência em pesquisa de lignina é orientar as vias biossintéticas que vão melhorar a degradação da lignina, uma vez que a lignina é capaz de copolimerizar com facilidade as unidades alternativas que derivam a biossíntese monolignóis, podendo polimerizar o ferulato coniferílico em conjunto com monolignóis normais nas paredes celulares primárias de milho. A lignina resultante é fortemente enriquecida em ligações éster que são facilmente quebráveis na espinha dorsal de lignina (Grabber et al., 2008).

A polimerização de lignina ocorre através radicalização oxidativa de fenóis, seguido por acoplamento radical combinatória. No primeiro passo, o fenol monolignóis é oxidado (ou seja, desidrogenado), formando um dímero. Em seguida, o dímero é desidrogenado novamente para um radical fenólico antes que possa acoplar com outro monômero radical, assim o polímero cresce uma unidade de cada vez. Como a estrutura de lignina depende da disponibilidade de radicais monolignóis, as peroxidases podem determinar, em parte, a estrutura final dos polímeros de lignina. Em gramíneas o p-cumarato, ao contrário do álcool sinapil, é um excelente substrato para peroxidases (Vanholme et al., 2010).

A expressão de genes responsáveis pelas enzimas CCoAOMT e o $\mathrm{F} 5 \mathrm{H}$ foram estudadas em transgênicos de Arabidopsis (Arabidopsis thaliana), milho (Zea mays), alfafa (Medicago sativa) e tabaco (Nicotiana tabacum) e se concluiu que a redução da expressão de cada gene, exceto F5H, reduz a quantidade de lignina na parede da célula em diferentes graus (Day et al., 2009; $\underline{\text { Vanholme et al., }}$ 2008). O silenciamento de $\mathrm{HCT}$ ou $\mathrm{C} 3 \mathrm{H}$ produz maior proporção de $\mathrm{p}$-hidroxifenil, a infraregulação da F5H ou COMT reduz fortemente o conteúdo de unidades siringil e a sobreregulação de F5H aumenta o teor das unidades de siringil, a infraregulação de CAD aumenta a incorporação de cinamaldeídos. Todas essas mudanças de composição têm repercussões sobre a estrutura do polímero e pode alterar as propriedades da parede celular (Vanholme et al., 2010).

Assim, os diversos fatores estressantes, sejam eles de natureza abióticas ou bióticas, afetam o nível de expressão de genes da via de lignina e também a expressão de genes envolvidos num grande número de outros processos biológicos, aparentemente não relacionadas, refletindo a nível metabólico (Dauwe et al., 2007; Leplé et al., 2007). Em estudos conduzidos por Zhong et al. (2007, 2008) e Zhou et al. (2009), o gene SND1 foi capaz de regular pelo menos 10 outros fatores de transcrição, alguns dos quais ativado da via dos fenilpropanóides como por exemplo, Myb46, Myb63, e Myb58. O entendimento desses processos poderá elucidar as modificações da lignina durante a dinâmica de crescimento e desenvolvimento das plantas.

\section{Biossíntese de lignina em condições de estresse hídrico}

Os três monômeros principais da lignina (cumaril, sinapil e coniferil) diferem entre si pelo seu grau de metilação, no qual suas proporções variam nas plantas não somente em função de diferenças entre espécies, como também dentro da própria espécie poderá haver diferenças em virtude das respostas dessas plantas aos fatores estressantes, visto que na biossíntese da lignina vária enzimas estão envolvidas e podem responder de forma diferente, na qual a lignina pode ter a sua produção aumentada ou apresentar mudanças em sua composição química, visto que a biossíntese da lignina é o resultado de uma complexa rede genética (Rogers \& Campbell, 2004), (Figura 6). Conforme Damasceno et al. (2010), a compreensão dos fatores que desencadeiam a expressão dos genes de lignina pode subsidiar a formação de modelos para melhor compreender os controles genéticos da síntese de lignina e a sua deposição na parede celular. 
$\mathrm{Na}$ literatura, observa-se que os fatores estressantes abióticos ainda são pouco estudados, pouco se sabe sobre os seus efeitos na biossíntese de lignina. O déficit hídrico, um fator que limita a produção de alimentos, tem relação direta com a deposição de lignina. As enzimas relacionadas à lignificação podem atuar isoladamente ou em combinação, induzindo os mecanismos de tolerância ao estresse em cinéticas diferentes devido a intensidades do déficit hídrico.

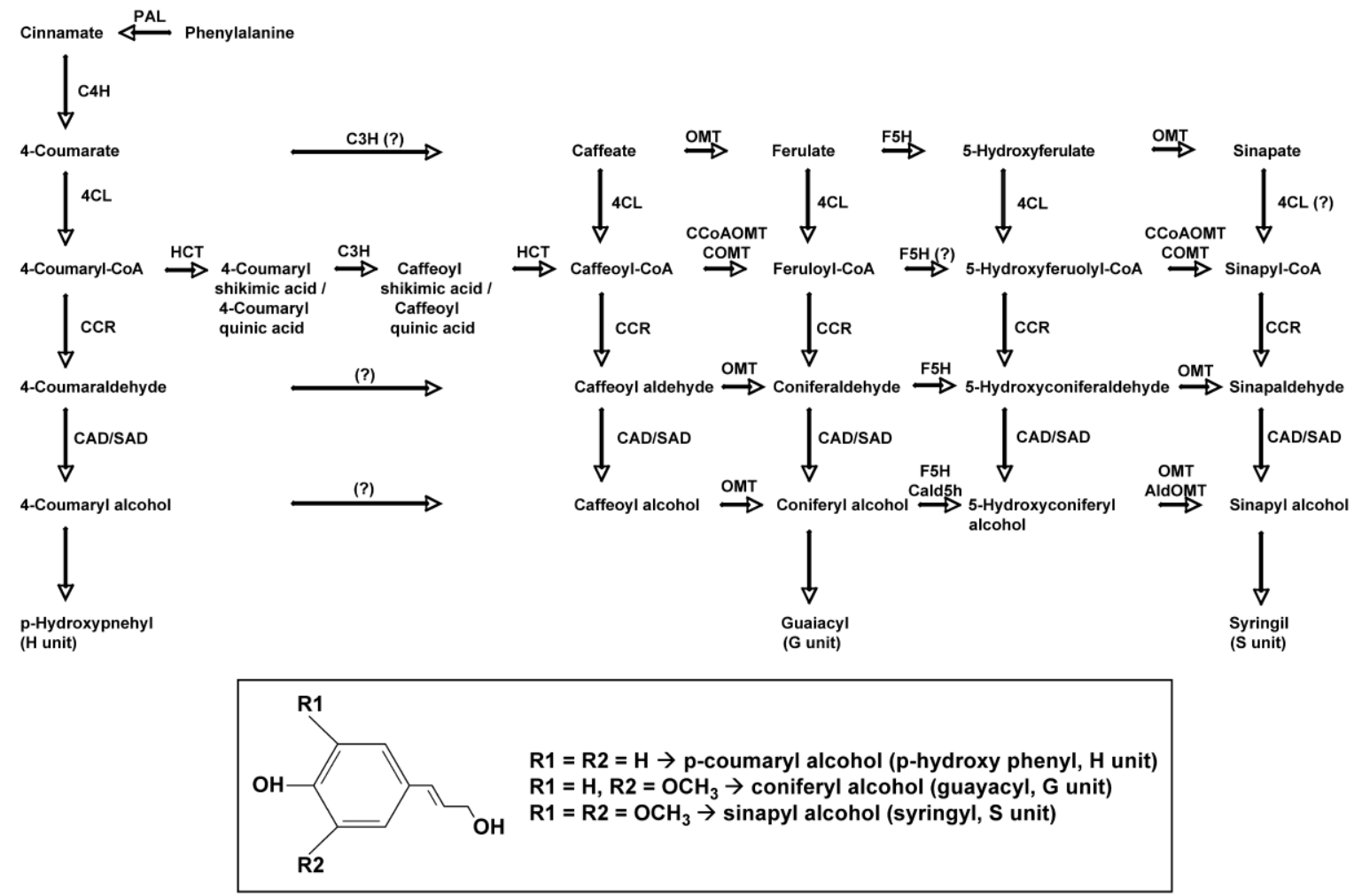

Figura 6. Biossíntese via de lenhina em plantas (adaptado a partir de Rastogi \& Dwivedi 2008). 4CL, 4-cumarato: coenzima A ligase; AldOMT, 5-hidroxi coniferaldeído O-metiltransferase; $\mathrm{C} 3 \mathrm{H}$, Cinamato 3 hidroxilase ou pcoumaroyl ácido/ácido quínico 3-hidroxilase chiquímico; $\mathrm{C} 4 \mathrm{H}$, Cinamato 4-hidroxilase; $\mathrm{CAD}$, cinamil álcool desidrogenase; Cald5H, coniferaldeído 5-hidroxilase; CCoAOMT, cafeoil coenzima A O-metiltransferase; CCR, cinamoilo coenzima A-redutase; F5H, ácido ferúlico 5-hidroxilase; HCT, p-hidroxi cinamoil-CoA: chiquimato/quinato phidroxi cinamoil-transferase; OMT, O-metiltransferase; PAL, fenilalanina amônia-liase; SAD, desidrogenase sinapyl álcool. Fonte: Silva et al. (2010).

Em estudos conduzidos por Alvarez et al (2008), observaram um aumento de percussores de lignina na seiva e redução da atividade enzimática da PAL em milho, indicando que a seca diminui a biossíntese da lignina no milho. Em outro trabalho com o milho, Fan et al. (2006), observaram que a parte basal das raízes reduziram mais o crescimento do que a parte apical e que este fator está associado a expressão dos genes Cinamoil-CoA I e II que estão envolvidos na síntese da lignina. Assim, o crescimento reduzido e maior proporção de lignina aumenta a disponibilidade de água e de nutrientes.

Em trabalho com Citrullus Lanatus, Yoshimura et al. (2007), observaram que a resistência da melancia a seca está condicionada a expressão de genes que codificam as enzimas $\mathrm{PAL}, \mathrm{C}_{3} \mathrm{H}$, 4cumarato coenzima A ligase (4CL), cafeoil coenzima A O-metiltransferase (CCoAOMT), álcool desidrogenase cinamil (CAD) e as peroxidases. Com o trevo branco (Trifolium repens), Lee et al. (2007), observaram que o estresse de 28 dias gerou redução no crescimento foliar e maior deposição de lignina, sendo que as respostas das enzimas a seca variaram no tempo, sendo que a PAL e o ascorbato peroxidase tiveram maior expressão até os 14 dias de estresse, diminuindo na sequência, e as peroxidases coniferílico e siringaldazina foram mais expressivas a partir do $14^{\circ}$ dia. A principal fase de lignificação deste trabalho ocorreu após 21 dias de déficit hídrico, quando o potencial hídrico foi de - 2,27 Mpa, correlacionando a um aumento na GPOC, CPOX e SPOX (Figura 7). 

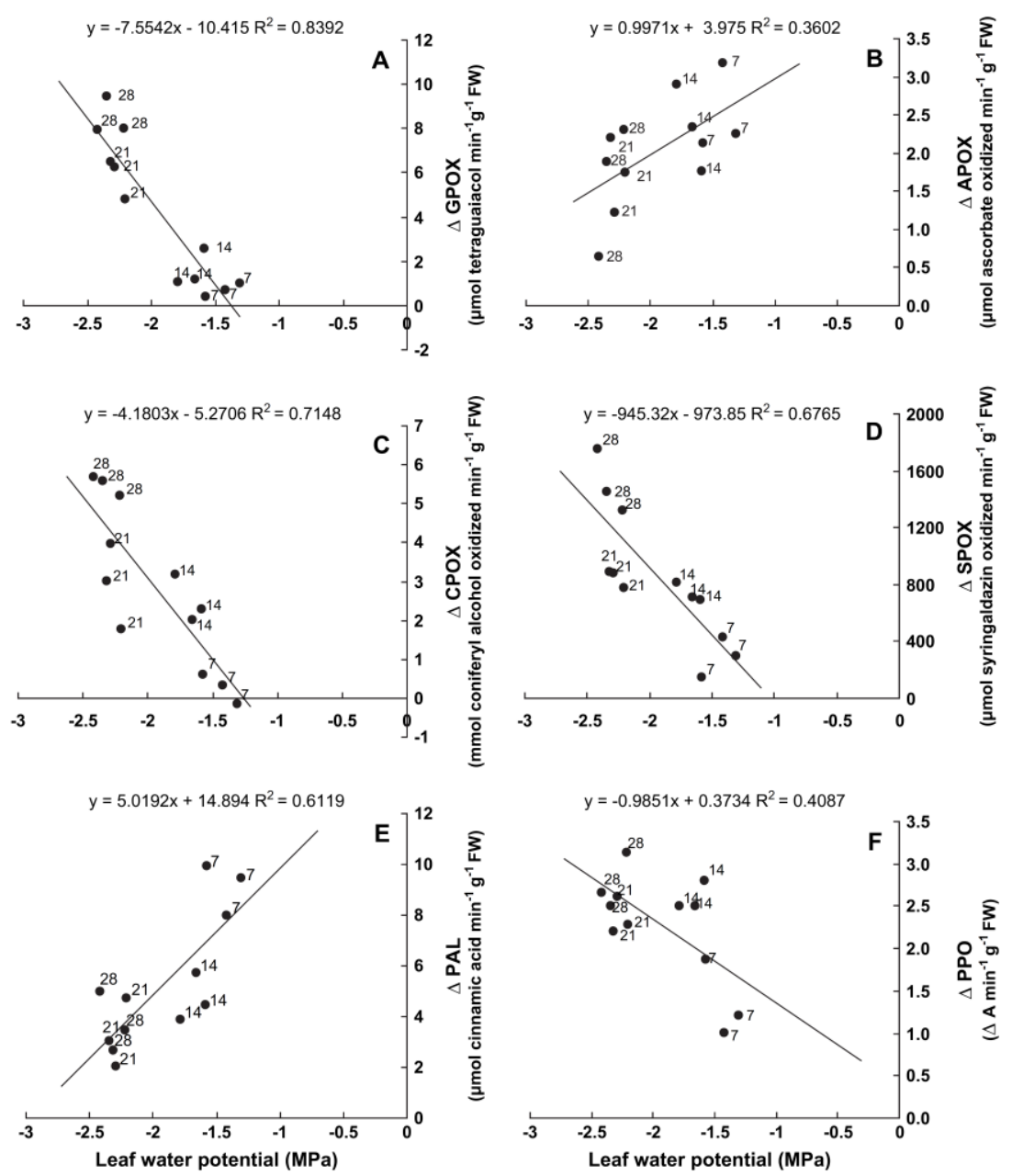

Figura 7. Gráficos de dispersão para a correlação entre potencial hídrico foliar (PD) no de déficit plantas estressadas e atividade de (A) peroxidase, GPOX; (B) ascorbato peroxidase, APOX; (C) álcool coniferílico peroxidase, CPOX; (D) siringaldazina peroxidase, SPOX; (E) fenilalanina amônia-liase, PAL, e (F) polifenol oxidase, PPO, em função de tratamento de déficit hídrico. Os valores são normalizados para a diferença (D) entre a atividade da enzima medido nas folhas com escassez de água e no bem regada (controle) folhas. Os números com cada símbolo indicam os dias após o tratamento. Fonte: Lee et al. (2007).

A condutância estomática foi significativamente menor em plantas sob estresse hídrico, aos 7-8 dias após a suspensão da irrigação (Figura 8), indicando que o estresse afetou a homeostasia da planta. Observa-se ainda que a condutância foliar e a pressão do xilema foi significativamente diferente do controle, confirmando que aos dias 7 e 8 após a retenção de água significam os estágios iniciais de estresse hídrico antes dos sinais hidráulicos.
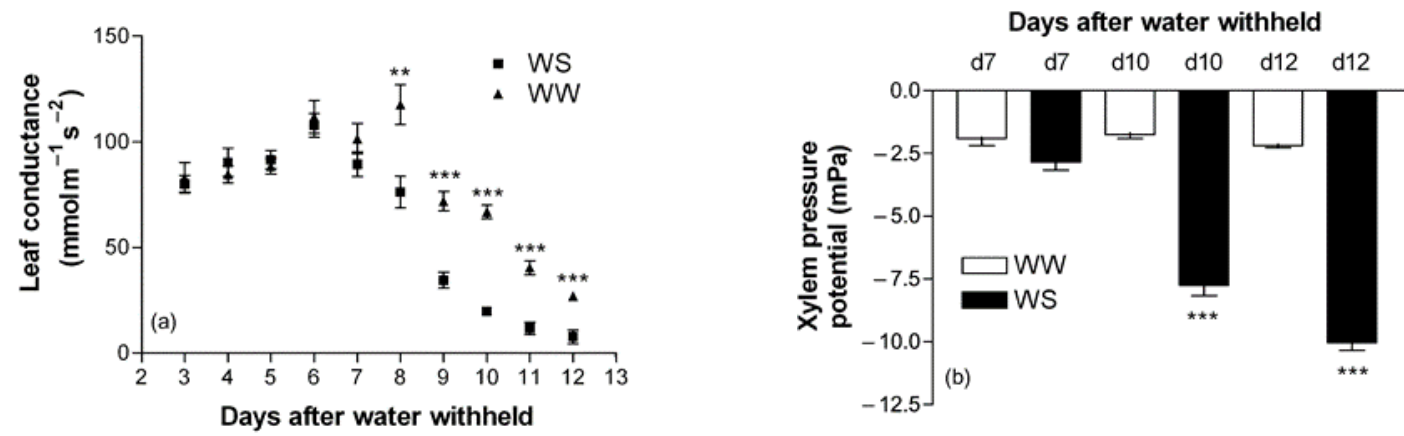

Figura 8. Condutância Folha (a) e potencial de pressão do xilema (b) para irrigada (WW) e plantas estressadas (WS). Diferenças significativas entre os tratamentos são indicados como ** $\mathrm{P}<0,01 \mathrm{e} * * * \mathrm{P}<0,001$. Fonte: Alvarez et al. $\underline{(2008)}$. 
No trabalho de Lee et al. (2007) os autores observaram que após 14 dias de déficit hídrico o potencial hídrico estava abaixo de 1,67 MPa, o aumento observado na GPOX, CPOX e SPOX (Figura 9) foi significativamente correlacionada com o aumento do teor de lignina. Tal como esperado, no dia 28 , quando o teor de lignina aumentaram 16\% nas folhas de déficit de água, algumas isozimas de GPOX SPO e foram muito mais fortemente expressas, salientando que as atividades de POX guaiacol e álcool coniferil foram espacialmente correlacionada com a produção de lignina em arranjo de agulhas, e sugeriu uma co-regulação de enzimas envolvidas na produção e polimerização de monolignóis.
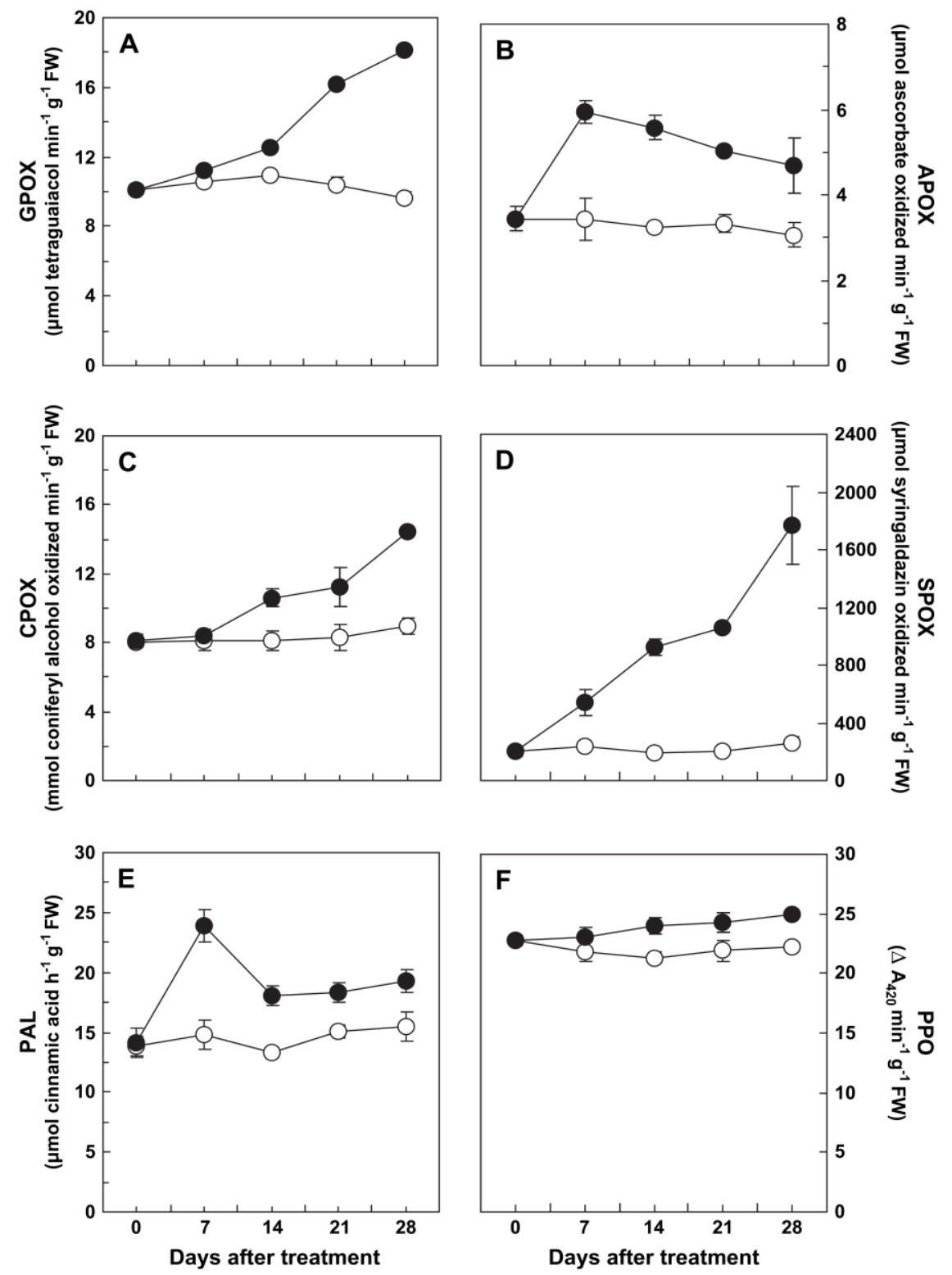

Figura 9. As alterações nas atividades de (A) peroxidase, GPOX.; (B) ascorbato peroxidase, APOX; (C) álcool coniferílico peroxidase, CPOX; (D) siringaldazina peroxidase, SPOX; (E) fenilalanina amônia-liase, PAL; e (F) polifenol oxidase, PPO, em déficit hídrico estressado (círculos cheios) e controle bem regada (círculos abertos), deixa de trevo branco. Fonte: Lee et al. (2007).

Alvarez et al. (2008) ainda observaram, mudanças mais significativas no conteúdo metabólito da seiva do xilema foram medidos 12 dias após a supressão da irrigação, principalmente no tratamento de estresse hídrico. Algumas tendências como, por exemplo, ABA e THR foram consistentes ao longo do período da seca, mas no dia 10, as diferenças não foram significativas (Figura 10). Uma forma conjugada de citocinina $Z R$ foi encontrada em maior abundância do que $Z$ e o BAP foi significativamente maior na seiva das plantas sob estresse em condições de seca severa nos dias 10 e 12. Já os ácidos orgânicos estavam presentes em abundância e foi significativamente maior em plantas sob estresse nos dias 7 e 12 . 


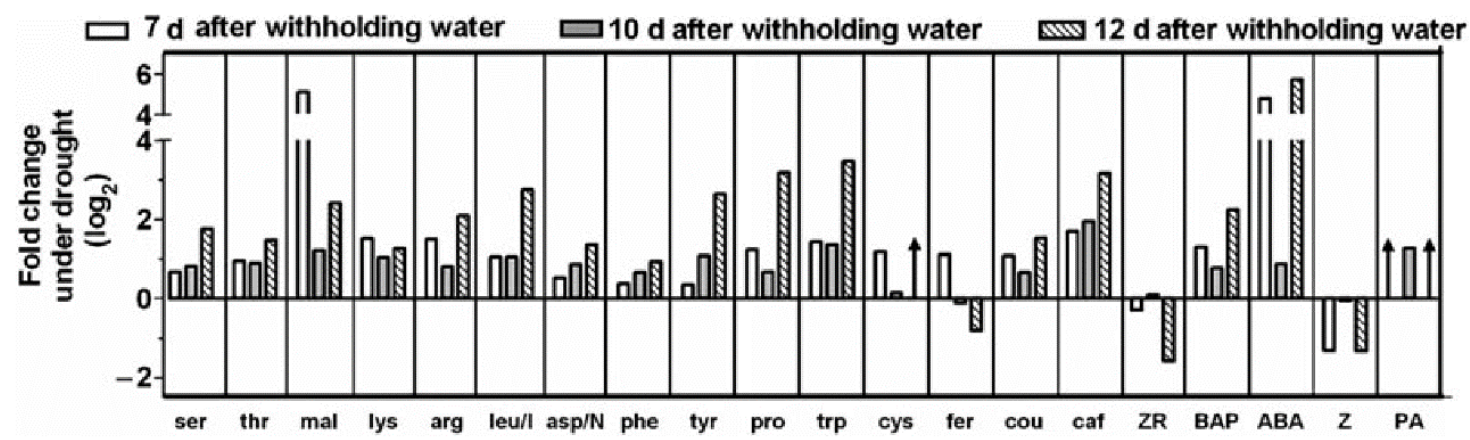

Figura 10. Dobro-mudança (D) $\left(\log _{2}\right)$ de metabólitos selecionados encontrados na seiva do xilema após 7,10 e 12 d de estresse hídrico. Fonte: Alvarez et al. (2008).

\section{Considerações finais}

A lignina proporciona maior rigidez estrutural, durabilidade dos tecidos, transporte de água nos vasos do xilema e funciona como uma barreia a ação patogênica, contudo, é responsável pela inibição do crescimento e pela complexação dos carboidratos e proteínas. As tensões bióticas e abióticas conduzem ao aumento da lignificação da parede celular ou a mudança de sua estrutura através das ações enzimáticas, contudo, pouco se sabe sobre essa dinâmica. Acredita-se que controles genéticos e fisiológicos complexos atuem modulando expressão de genes de lignina e que suas respostas ao déficit hídrico variam em função da espécie e da intensidade e duração do estresse, no qual as respostas das enzimas poderiam ser expressas isoladamente ou em conjunto, com a mesma cinética ou não. A elucidação da biossíntese da lignina contribuirá para os programas de melhoramento, para a formulação de modelos matemáticos e para um melhor manejo de pastagens.

\section{Referências bibliográficas}

Alvarez, S., Marsh, E. L., Schroeder, S. G., \& Schachtman, D. P. (2008). Metabolomic and proteomic changes in the xylem sap of maize under drought. Plant, Cell \& Environment, 31(3), 325-340. https://doi.org/10.1111/j.1365-3040.2007.01770.x

Balasundram, N., Sundram, K., \& Samman, S. (2006). Phenolic compounds in plants and agri-industrial by-products: Antioxidant activity, occurrence, and potential uses. Food Chemistry, 99(1), 191-203. https://doi.org/10.1016/j.foodchem.2005.07.042

Bauer, M. de O., Gomide, J. A., Silva, E. A. M., Regazzi, A. J., \& Chichorro, J. F. (2008). Anatomical evaluation and nutritive value of four prevailing forage grasses in natural pasture of Viçosa-MG. Revista Brasileira de Zootecnia, 37(1), 9-17.

Bezerra, J. D. C., Silva, P. T. V., Ferreira, G. D. G., Silva, D. K. A., Nascimento, W. G., Moura, J. G., Souza, R. T. A., \& Moraes, G. S. O. (2014). Diferenciações histológicas entre colmos de plantas de metabolismo C4 e CAM. IX Congresso Nordestino de Produção Animal - CNPA.

Boerjan W, Ralph J, Baucher M. (2003) Lignin biosynthesis. Annual Review of Plant Biology, 54: 519546.

Briskin, D. P. (2000). Medicinal Plants and Phytomedicines. Linking Plant Biochemistry and Physiology to Human Health. Plant Physiology, 124(2), 507-514. https://doi.org/10.1104/pp.124.2.507

Buxton, D. R. (1996). Quality-related characteristics of forages as influenced by plant environment and agronomic factors. Animal Feed Science and Technology, 59(1-3), 37-49. https://doi.org/10.1016/0377-8401(95)00885-3

Copani, G., Hall, J. O., Miller, J., Priolo, A., \& Villalba, J. J. (2013). Plant secondary compounds as complementary resources: are they always complementary? Oecologia, 172(4), 1041-1049. https://doi.org/10.1007/s00442-012-2551-1

Damasceno, C. M. B.; Sousa, S. M. de; Noda, R. W.; Parrella, R. A. da C.; Schaffert, R. E.; Magalhães, J. V. (2010). A importância da lignina para a produção de etanol de Segunda geração. Documento 108. Embrapa Milho e Sorgo. 
Dauwe, R., Morreel, K., Goeminne, G., Gielen, B., Rohde, A., Van Beeumen, J., Ralph, J., Boudet, A.M., Kopka, J., Rochange, S. F., Halpin, C., Messens, E., \& Boerjan, W. (2007). Molecular phenotyping of lignin-modified tobacco reveals associated changes in cell-wall metabolism, primary metabolism, stress metabolism and photorespiration. The Plant Journal, 52(2), 263-285. https://doi.org/10.1111/j.1365-313X.2007.03233.X

Day, A., Neutelings, G., Nolin, F., Grec, S., Habrant, A., Crônier, D., Maher, B., Rolando, C., David, H., Chabbert, B., \& Hawkins, S. (2009). Caffeoyl coenzyme A O-methyltransferase down-regulation is associated with modifications in lignin and cell-wall architecture in flax secondary xylem. Plant Physiology and Biochemistry, 47(1), 9-19. https://doi.org/10.1016/j.plaphy.2008.09.011

Fan, L., Linker, R., Gepstein, S., Tanimoto, E., Yamamoto, R., \& Neumann, P. M. (2006). Progressive Inhibition by Water Deficit of Cell Wall Extensibility and Growth along the Elongation Zone of Maize Roots Is Related to Increased Lignin Metabolism and Progressive Stelar Accumulation of Wall Phenolics. Plant Physiology, 140(2), 603-612. https://doi.org/10.1104/pp.105.073130

Grabber, J. H., Hatfield, R. D., Lu, F., \& Ralph, J. (2008). Coniferyl Ferulate Incorporation into Lignin Enhances the Alkaline Delignification and Enzymatic Degradation of Cell Walls. Biomacromolecules, 9(9), 2510-2516. https://doi.org/10.1021/bm800528f

Grotewold, E. (2005). Plant metabolic diversity: a regulatory perspective. Trends in Plant Science, 10(2), 57-62. https://doi.org/10.1016/j.tplants.2004.12.009

Kaur, C., \& Kapoor, H. C. (2008). Antioxidants in fruits and vegetables - the millennium's health. International Journal of Food Science \& Technology, 36(7), 703-725. https://doi.org/10.1111/j.1365-2621.2001.00513.x

Kim, H., Ralph, J., Lu, F., Ralph, S. A., Boudet, A.-M., MacKay, J. J., Sederoff, R. R., Ito, T., Kawai, S., Ohashi, H., \& Higuchi, T. (2003). NMR analysis of lignins in CAD-deficient plants. Part 1. Incorporation of hydroxycinnamaldehydes and hydroxybenzaldehydes into lignins. Organic \& Biomolecular Chemistry, 1(2), 268-281. https://doi.org/10.1039/b209686b

Lee, B.-R., Kim, K.-Y., Jung, W.-J., Avice, J.-C., Ourry, A., \& Kim, T.-H. (2007). Peroxidases and lignification in relation to the intensity of water-deficit stress in white clover (Trifolium repens L.). Journal of Experimental Botany, 58(6), 1271-1279. https://doi.org/10.1093/jxb/erl280

Leplé, J.-C., Dauwe, R., Morreel, K., Storme, V., Lapierre, C., Pollet, B., Naumann, A., Kang, K.-Y., Kim, H., Ruel, K., Lefèbvre, A., Joseleau, J.-P., Grima-Pettenati, J., Rycke, R., Andersson-Gunnerås, S., Erban, A., Fehrle, I., Petit-Conil, M., Kopka, J., ... Boerjan, W. (2007). Downregulation of Cinnamoyl-Coenzyme A Reductase in Poplar: Multiple-Level Phenotyping Reveals Effects on Cell Wall Polymer Metabolism and Structure. The Plant Cell, 19(11), 3669-3691. https://doi.org/10.1105/tpc.107.054148

Moura, J. C. M. S., Bonine, C. A. V., Oliveira Fernandes Viana, J., Dornelas, M. C., \& Mazzafera, P. (2010). Abiotic and Biotic Stresses and Changes in the Lignin Content and Composition in Plants. Journal of Integrative Plant Biology, 52(4), 360-376. https://doi.org/10.1111/j.17447909.2010.00892.x

Naczk, M., \& Shahidi, F. (2004). Extraction and analysis of phenolics in food. Journal of Chromatography A, 1054(1-2), 95-111. https://doi.org/10.1016/j.chroma.2004.08.059

Ralph, J. (1996). Cell Wall cross-linking in grasses: the importance of understanding plant chemistry and biochemistry. International Conference with Dairy and Forage Industries, US DAIRY RESEARCH CENTER.

Rastogi, S. \& Dwivedi, U. N. (2008). Manipulation of lignin in plants com especial referência a Ometiltransferase. Plant Science.174,264-277.

Rippert, P., Puyaubert, J., Grisollet, D., Derrier, L., \& Matringe, M. (2009). Tyrosine and Phenylalanine Are Synthesized within the Plastids in Arabidopsis. Plant Physiology, 149(3), 1251-1260. https://doi.org/10.1104/pp.108.130070

Rogers, L. A., \& Campbell, M. M. (2004). The genetic control of lignin deposition during plant growth and development. New Phytologist, 164(1), 17-30. https://doi.org/10.1111/j.14698137.2004.01143.x 
Saliba, E. de O. S., Rodriguez, N. M., Morais, S. A. L., \& Piló-Veloso, D. (2001). Lignins: Isolation methods and chemical characterization. Ciência Rural, 31(5), 917-928.

Silva, J. C. M; Bonine, C. A. V.; Viana, J. de O. F.; Dornelas, M. C.; Mazzafera, P. (2010) Abiotic and Biotic Stresses and Changes in the Lignin Content and Composition in Plants. J. Integr. Plant Biol. $2010,52,360-376$.

Singer, M. S., Mace, K. C., \& Bernays, E. A. (2009). Self-Medication as Adaptive Plasticity: Increased Ingestion of Plant Toxins by Parasitized Caterpillars. PLoS ONE, 4(3), e4796. https://doi.org/10.1371/journal.pone.0004796

Soares, S. E. (2002). Acidos fenólicos como antioxidantes. Revista de Nutrição, 15(1), 71-81.

Taiz, L., \& Zeiger, E. (2004). Surface protection and secondary defense compounds. In Plant Physiology (Vol. 2, pp. 320-345). The Benjamin/Cummings Redwood City, Menlo Park, Reading, New York, Don Mills ....

Vanholme, R, Morreel, K., Ralph, J., \& Boerjan, W. (2008). Lignin engineering. Current Opinion in Plant Biology, 11(3), 278-285. https://doi.org/10.1016/j.pbi.2008.03.005

Vanholme, Ruben, Demedts, B., Morreel, K., Ralph, J., \& Boerjan, W. (2010). Lignin Biosynthesis and Structure. Plant Physiology, 153(3), 895-905. https://doi.org/10.1104/pp.110.155119

Villalba, J. J., \& Landau, S. Y. (2012). Host behavior, environment and ability to self-medicate. Small Ruminant Research, 103(1), 50-59. https://doi.org/10.1016/j.smallrumres.2011.10.018

Wilson, J. R. (1994). Cell wall characteristics in relation to forage digestion by ruminants. The Journal of Agricultural Science, 122(2), 173-182. https://doi.org/10.1017/S0021859600087347

Yoshimura, K., Masuda, A., Kuwano, M., Yokota, A., \& Akashi, K. (2007). Programmed Proteome Response for Drought Avoidance/Tolerance in the Root of a C3 Xerophyte (Wild Watermelon) Under Water Deficits. Plant and Cell Physiology, 49(2), 226-241. https://doi.org/10.1093/pcp/pcm180

Zhong, R., Lee, C., Zhou, J., McCarthy, R. L., \& Ye, Z.-H. (2008). A Battery of Transcription Factors Involved in the Regulation of Secondary Cell Wall Biosynthesis in Arabidopsis. The Plant Cell, 20(10), 2763-2782. https://doi.org/10.1105/tpc.108.061325

Zhong, R., Richardson, E. A., \& Ye, Z.-H. (2007). The MYB46 Transcription Factor Is a Direct Target of SND1 and Regulates Secondary Wall Biosynthesis in Arabidopsis. The Plant Cell, 19(9), 27762792. https://doi.org/10.1105/tpc.107.053678

Zhou, J., Lee, C., Zhong, R., \& Ye, Z.-H. (2009). MYB58 and MYB63 Are Transcriptional Activators of the Lignin Biosynthetic Pathway during Secondary Cell Wall Formation in Arabidopsis. The Plant Cell, 21(1), 248-266. https://doi.org/10.1105/tpc.108.063321

Recebido: 29 de abril, 2020.

Aprovado: 6 de junho, 2020

Disponível online: 18 de setembro, 2020.

Licenciamento: Este artigo é publicado na modalidade Acesso Aberto sob a licença Creative Commons Atribuição 4.0 (CC-BY 4.0), a qual permite uso irrestrito, distribuição, reprodução em qualquer meio, desde que o autor e a fonte sejam devidamente creditados. 